\title{
Dye-Sensitization Observed in Photoelectrochemically Etched $n$-Type Gallium Nitride
}

\author{
Sadayuki Kikawa, Tomohiro Gonda, and Naoki Kobayashi* \\ Department of Applied Physics and Chemistry, The University of Electro-Communications, Chofu, Tokyo 182-8585, Japan
}

(Received 15 February 2010; Accepted 9 March 2010; Published 22 May 2010)

\begin{abstract}
The sensitization in visible light region is observed by the adsorption of N3 (bis [(4,4'-dicarboxy-2,2'bipyridyl)(NCS)] $\mathrm{Ru}(\mathrm{II})$ ) dye on photoelectrochemically etched $n$-GaN surface. From the incident photon to current efficiency spectrum, the sensitization in visible light region and its enhancement with the increase of surface roughening is observed, but the sensitization decreases by the excess etching. From the excitation intensity dependence of photocurrent at $546 \mathrm{~nm}$ wavelength, the electron transfer from the excited N3 dye to $n$-GaN occurs via one-photon process, not via intermediate states. The solar cell is fabricated using $\mathrm{I}_{2} / \mathrm{LiI}$ in acetonitrile as the electrolyte and Pt sputtered fluoride tin oxide glass as the counter electrode. According to the solar simulator measurement at AM1.5G, the short-circuit current density and the conversion efficiency are $0.6 \mathrm{~mA} \cdot \mathrm{cm}^{-2}$ and $0.27 \%$, respectively. The low adsorbed dye amount on the etched $n$-GaN surface is the cause for these small current and efficiency values, but the current per adsorbed $\mathrm{N} 3$ dye molecule is comparable with the $\mathrm{N} 3 \mathrm{dye} / \mathrm{TiO}_{2}$ nano-porous layer system by BET surface area measurement and dye dissolution experiment. To reflect wide-bandgap of GaN, the open-circuit voltage of $0.71 \mathrm{~V}$ and the fill factor of 0.64 are also comparable with the dye-sensitized solar cells using $\mathrm{TiO}_{2}$ nano-porous layer. [DOI: 10.1380/ejssnt.2010.254]
\end{abstract}

Keywords: Gallium nitride; Photochemistry; Surface electrical transport; Electrochemical methods; Surface roughening; Dye-sensitization; Photoelectrochemical etching; Incident photon to current efficiency

\section{INTRODUCTION}

Dye-sensitized solar cell (DSSC), developed by O'Regan and Grätzel [1], is photoelectric conversion device using visible light excitation of dye adsorbed on porous semiconductor surface. It attracts much attention as a next generation solar cell because of low cost and high efficiency $(11 \%)$ [2]. Generally, spreading the paste of oxide semiconductor nano-particle, such as titanium dioxide $\left(\mathrm{TiO}_{2}\right)[1,2]$ or zinc oxide $(\mathrm{ZnO})[3]$ on the conductive glass and then annealing are used for fabricating the nanoporous semiconductor layer of DSSC. The nano-porous layer can adsorb a large amount of dye molecules owing to its large specific surface area. In the electrolyte, it has been proposed that the electron transport in nanoporous layer is held by the diffusion based on the ambipolar model $[4,5]$. But according to the high-temperature Hall effect measurement, the electron mobility of the $\mathrm{TiO}_{2}$ nano-porous layer with about $13 \mu \mathrm{m}$ thickness was as low as $6 \mathrm{~cm}^{2} \mathrm{~V}^{-1} \mathrm{~s}^{-1}$ in the condition of carrier activation at $500 \mathrm{~K}[6]$. Such a low mobility is partly due to the transport through the necking of nano-particles. The application of oxide semiconductor nano-porous layer to solar cells was very successful so far, but low electron mobility might become disadvantage in further development for higher efficiency DSSCs.

In this study, the dye-sensitization in $n$-GaN was investigated. GaN is attractive for high-performance and robust solar cell devices because it has the following properties: a wide $(3.4 \mathrm{eV})$ and direct bandgap, high carrier mobility and high thermally/chemically stability. The solar cell using $p$-GaN nanorods on $n$-Si has been reported by Tang et al. [7], but no DSSC using GaN has been reported so far. The $n$-GaN sample used in this experiment has an electron mobility of $140 \mathrm{~cm}^{2} / \mathrm{Vs}$ at room temperature. Therefore, because there is a strong upward band-bending toward the surface, it is expected that the electron-hole

*Corresponding author: naoki@pc.uec.ac.jp separation is enhanced at the dye $/ n$-GaN interface. And moreover, it is also prospective that the injected electrons are fast transported in $n$-GaN when electrons are transferred from the excited dyes to $n$-GaN. The conductionband edge in $n$-GaN, which is located at about $0.4 \mathrm{eV}$ higher than that of $\mathrm{TiO}_{2}$ [8], has a possibility of increasing open-circuit voltage.

To increase the adsorbed dye amount on $n$-GaN surface, the surface was roughened by photoelectrochemical (PEC) etching. The PEC etching is a wet method based on the dissolution of the semiconductor layer during photoexcitation in basic solution [9]. It has been reported that the PEC etching of (0001) face of $n$-GaN gives a high density $\left(\sim 10^{9} \mathrm{~cm}^{-2}\right)$ rod- or whisker-like nano-structures with a diameter of several tens of nanometers [10].

In this paper, the visible light sensitization was observed by N3 (Bis [(4,4'-dicarboxy -2,2'- bipyridyl)(NCS)] $\mathrm{Ru}(\mathrm{II}))$ dye adsorption on the PEC etched $n$-GaN surface. The change in incident photon to current efficiency (IPCE) spectrum with the degree of etching was reported and the photosensitization process was discussed by the result of the dependence of photocurrent on excitation intensity. Finally, the characteristics of GaN based DSSC using N3 dye and PEC etched $n$-GaN were reported and discussed.

\section{EXPERIMENTS}

Si-doped $n$-GaN grown by metallorganic vapor phase epitaxy on sapphire substrate (carrier concentration: $1 \times 10^{18} \mathrm{~cm}^{-3}$, thickness of $n$-GaN layer: $2 \mu \mathrm{m}$ ) was used for the GaN based DSSC. The $n$-GaN layer was fabricated after the growth of $2 \mu \mathrm{m}$ undoped GaN. The dislocation density was about $10^{9} \mathrm{~cm}^{-2}$. After depositing $\mathrm{Al} / \mathrm{Au}$ ohmic contact, the surface of $n$-GaN was photoelectrochemically etched in $0.02 \mathrm{M} \mathrm{KOH}$ aqueous solution under the $365 \mathrm{~nm}$ light from Hg-Xe lamp filtered by $10 \%$ $\mathrm{CuSO}_{4}$ aqueous solution. The intensity of excitation light was about $200 \mathrm{~mW} \cdot \mathrm{cm}^{-2}$ and its spot size was $4 \mathrm{~mm} \phi$. The three electrode system including $n$-GaN working electrode, $\mathrm{Pt}$ counter electrode and $\mathrm{Ag} / \mathrm{AgCl}$ reference elec- 


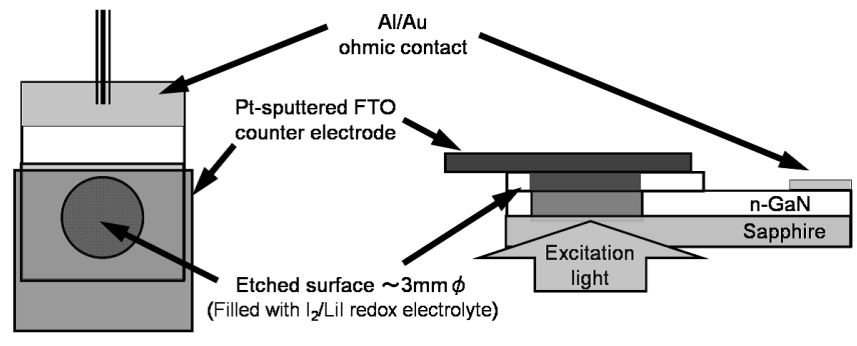

FIG. 1: Schematic Image of the $n$-GaN based DSSC.

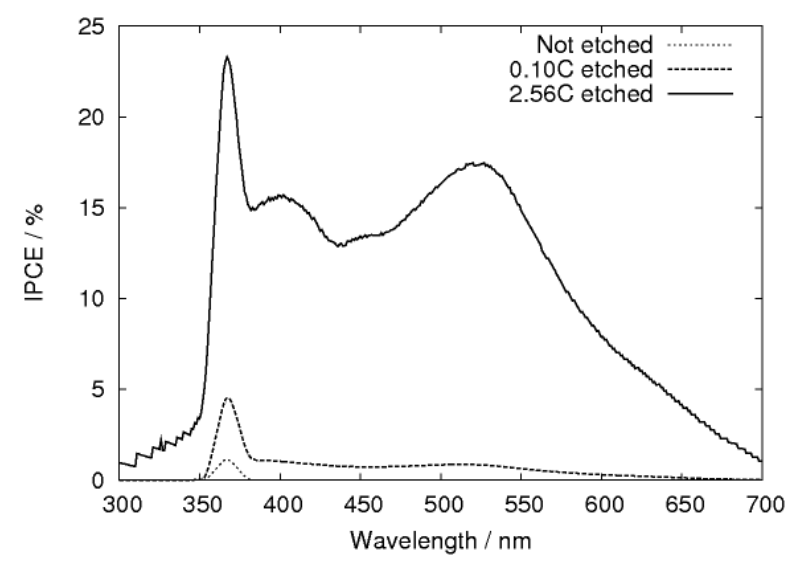

FIG. 2: IPCE spectra of the DSSC using dye-adsorbed $n$-GaN.

trode mediated by the potentiostat (HAB-151, Hokuto Corp.) were used for the PEC etching. The progress of PEC etching was monitored by measuring the spent charge amount estimated from the photocurrent during etching.

The etched $n$-GaN was dipped for 20 hours in $0.2 \mathrm{mM}$ ethanol solution of N3 dye for dye adsorption. Figure 1 shows the schematic diagram of the GaN based DSSC. Pt sputtered conductive fluoride tin oxide (FTO) glass and acetonitrile solution of $0.05 \mathrm{M} \mathrm{I}_{2}$ and $0.5 \mathrm{M} \mathrm{LiI}$ were used for the counter electrode and the electrolyte, respectively. The electrolyte solution in DSSC was sealed by filling the electrolyte in the $5.5 \mathrm{~mm} \phi$ hole of $500 \mu \mathrm{m}$ thick spacer. The photoexcitation was done from the transparent sapphire substrate side.

Incident photon to current efficiency (IPCE) spectrum was measured by plotting photocurrent under monochromatic light irradiation from $100 \mathrm{~W}$ Xe lamp (LAX101, Asahi Spectra Co., Ltd.). The dependence of photocurrent on photointensity was measured by $546 \mathrm{~nm}$ light from 200 W Hg-Xe lamp (L2570, Hamamatsu Photonics K.K.). $\mathrm{I}-\mathrm{V}$ characteristics and conversion efficiency of DSSC were measured by the solar simulator using AM1.5G sunlight (Light source: $300 \mathrm{~W}$ Xe lamp, LHX-500E3, Peccell Technologies) with the intensity of $100 \mathrm{~mW} \cdot \mathrm{cm}^{-2}$. The active cell area was $0.24 \mathrm{~cm}^{2}(5.5 \mathrm{~mm} \phi)$ in all measurements.

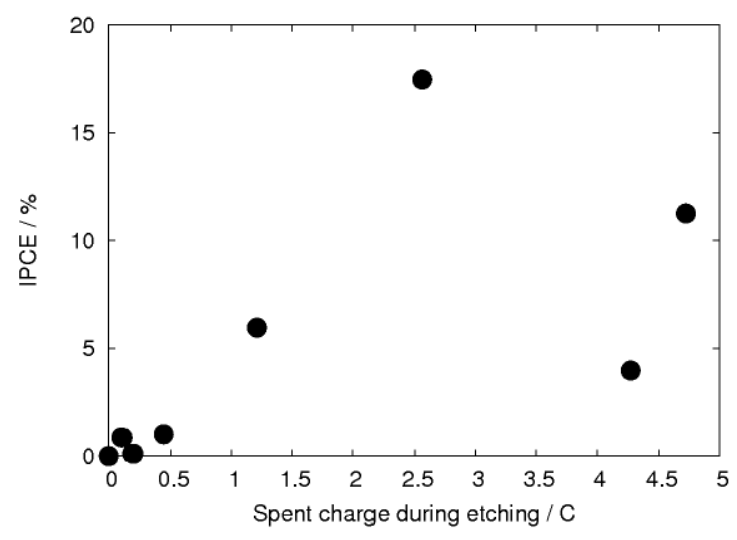

FIG. 3: Dependence of IPCE on etched amount.

\section{RESULTS AND DISCUSSION}

Figure 2 shows the IPCE spectra of the GaN based DSSC. The sample using not etched n-GaN shows only $367 \mathrm{~nm}$ peak, which is due to the GaN absorption affected by the strong absorption of $\mathrm{I}_{2}$ in electrolyte solution and also by the low excitation intensity in UV region. In contrast, the broad peak appeared in the visible region for the $0.10 \mathrm{C}$ etched sample. And for the $2.56 \mathrm{C}$ etched sample, the visible region $530 \mathrm{~nm}$ peak increased up to $17.5 \%$. The peaks at $530 \mathrm{~nm}$ and $400 \mathrm{~nm}$ are the evidence for sensitization by N3 dye because two peaks are located near the absorption peaks of $\mathrm{N} 3$ dye in solution [11, 12]. It is considered that the N3 dye is chemically bonded with the thin oxide layer on the GaN surface after PEC etching like the Ti-O linkage reported for N3 dye adsorption on $\mathrm{TiO}_{2}$ surface [13]. It was also found that the GaN related peak at $367 \mathrm{~nm}$ increases by etching. This is due to the enhanced optical confinement by light scattering of roughened GaN surface.

The dependence of $530 \mathrm{~nm}$ peak intensity in the IPCE spectrum on the total charge spent during PEC etching was shown in Fig. 3. Below $2.5 \mathrm{C}$, the peak intensity increased with the degree of etching, indicating the increase in surface area and adsorbed dye amount. However, over $2.5 \mathrm{C}$, the peak intensity decreased. This is attributed to the excess GaN etching. Figure 4 shows the SEM images of $n$-GaN surfaces at $2.56 \mathrm{C}$ and at $4.27 \mathrm{C}$ etching. For the surface of $4.27 \mathrm{C}$ etching, the density of $\mathrm{GaN}$ whisker decreases as compared with the surface of $2.56 \mathrm{C}$ etching and the whiskers become thinner with less than $20 \mathrm{~nm} \phi$. Some whiskers break down and the sapphire substrate surface partially appears by complete etching of GaN layer. It is considered that the current for the excess PEC etching flows through high-resistive undoped GaN layer partially left after etching in $4.27 \mathrm{C}$ etched $\mathrm{GaN}$, in contrast with the $2.56 \mathrm{C}$ etched sample which was etched less than $2 \mu \mathrm{m}$ and the $n$-GaN layer still remained. And the depletion layer, its width of $n$-GaN with $10^{18} \mathrm{~cm}^{-3}$ carrier concentration is calculated as about several tens of nanometers, also behaves as resistance in highly etched $n$-GaN. The BET surface area for the etched $2 \mu \mathrm{m}$ thick $n$-GaN sample showing the maximum sensitization is measured as $2 \mathrm{~m}^{2} / \mathrm{g}$, which is about $1 / 25$ of $10 \mu \mathrm{m}$ thick $\mathrm{TiO}_{2}$ nano- 
(a)

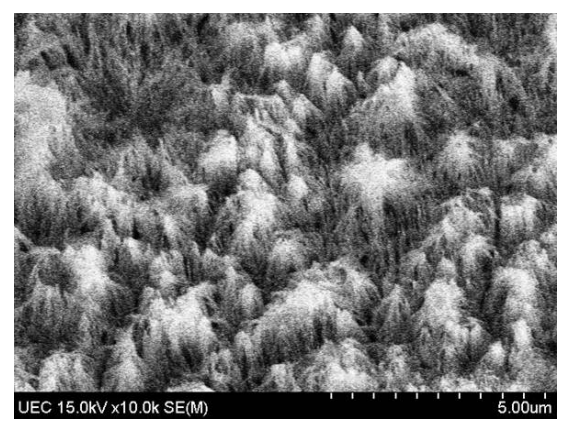

(b)

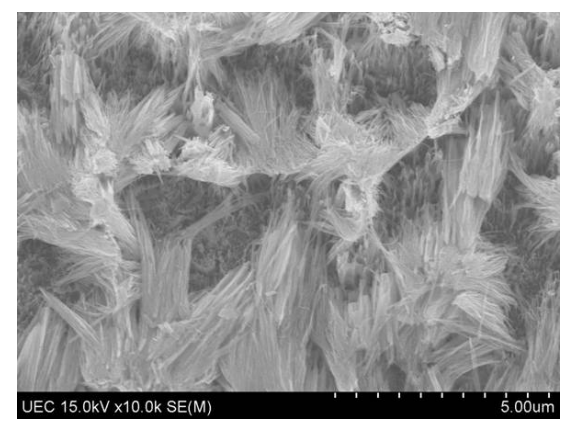

FIG. 4: SEM images for the surfaces of etched $n$-GaN. (a) $2.56 \mathrm{C}$ etched/(b) $4.27 \mathrm{C}$ etched.

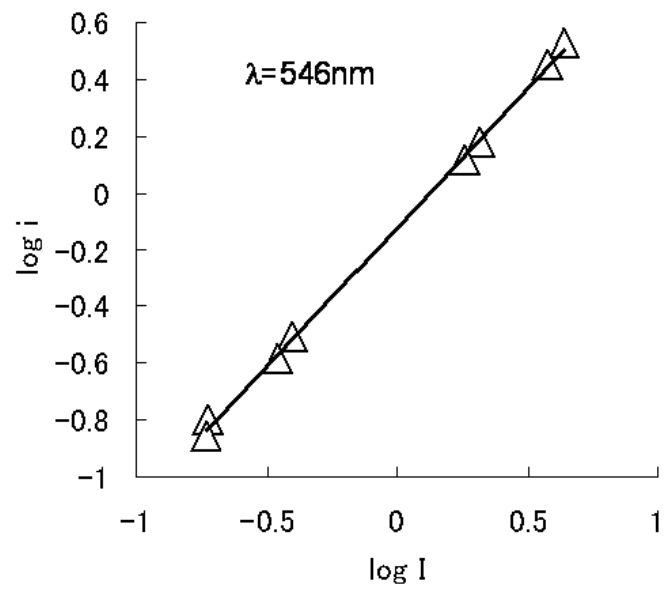

FIG. 5: Dependence of the photocurrent of $n$-GaN based DSSC on photointensity (log-log plot).

porous layer.

The logarithmic plot of photocurrent vs. photointensity on the GaN based DSSC was shown in Fig. 5. As observed for the $\mathrm{TiO}_{2}$ based DSSC, the slope of the plot was very close to one, indicating that the electron transfer from the excited N3 dye to conduction band of $n$-GaN occurs via one-photon process. It means that the photoexcitation of N3 dye and carrier injection to the conduction band of $n$-GaN occurs directly, not via intermediate states.

Figure 6 shows the I-V curve for the GaN based DSSC under AM1.5G sunlight irradiation. The short-circuit current density $\left(J_{\mathrm{SC}}\right)$ and the conversion efficiency were $0.6 \mathrm{~mA} \cdot \mathrm{cm}^{-2}$ and $0.27 \%$, respectively. These small values are caused by still low adsorbed dye amount for the

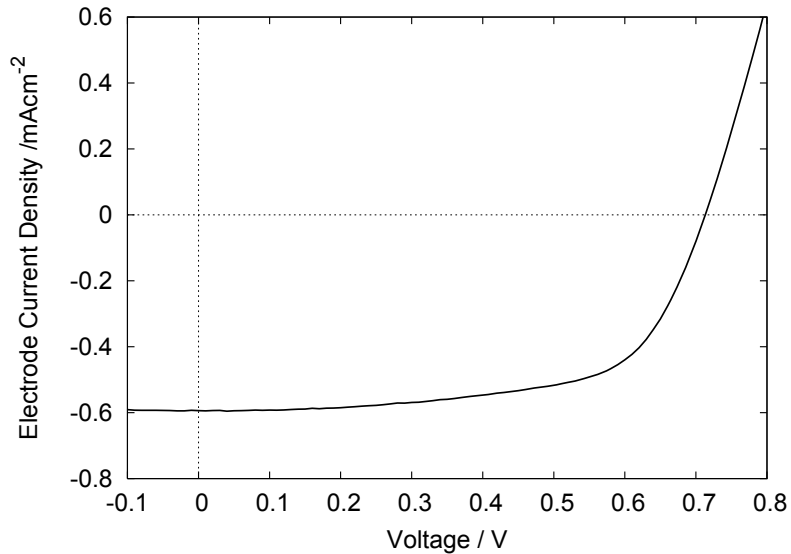

FIG. 6: I-V curve of the etched $n$-GaN based DSSC under AM1.5G sunlight irradiation.

etched $n$-GaN surface, which was confirmed by BET surface area measurement. From the dye-density experiment by $\mathrm{NaOH}$ solution, N3 dye amount adsorbed on PEC etched $2 \mu \mathrm{m}$ thick $n$-GaN was in the low range of $10^{-6} \mathrm{~mol} \cdot \mathrm{cm}^{-3}$, in contrast with $3.2 \times 10^{-5} \mathrm{~mol} \cdot \mathrm{cm}^{-3}$ for the $\mathrm{TiO}_{2}$ nano-porous layer with $10 \mu \mathrm{m}$ thickness. Therefore it can be said that the current per adsorbed N3 dye molecules is comparable with $\mathrm{TiO}_{2}$ based DSSC. To reflect wide-bandgap of GaN, the open-circuit voltage of $0.71 \mathrm{~V}$ and the fill factor of 0.64 were also comparable with the $\mathrm{TiO}_{2}$ based DSSC.

To increase JSC and conversion efficiency in the present GaN based DSSC, thicker GaN layer must be used to increase the specific surface area. At present, the effect of high electron mobility and surface band-bending by GaN on the characteristics of DSSC is not clear. The timeresolved measurement to know the lifetime of the electron transfer from the dye to GaN also will have to be studied.

\section{CONCLUSIONS}

The visible light sensitization was observed by the DSSC using N3 dye adsorption on PEC etched $n$-GaN. The increase in the incident photon to current efficiency (IPCE) in the visible light region with the degree of etching was observed. Furthermore, the electron transfer from the excited N3 dye to $n$-GaN occurred via one-photon process from the excitation intensity dependence of photocurrent in the visible region. The JSC and the conversion efficiency were still low of $0.6 \mathrm{~mA} \cdot \mathrm{cm}^{-2}$ and $0.27 \%$, respectively. These are due to low adsorbed dye amount for the etched $n$-GaN surface, but the current per adsorbed N3 due molecule is comparable with $\mathrm{TiO}_{2}$ based DSSC. To reflect wide-bandgap of $\mathrm{GaN}$, the open-circuit voltage of $0.71 \mathrm{~V}$ and the fill factor of 0.64 were also comparable with the $\mathrm{TiO}_{2}$ based DSSC.

\section{Acknowledgments}

The authors appreciate Taiyo Nippon Sanso EMC Ltd. for the supply of $n$-GaN epitaxial wafer and the conve- 
nience of SEM measurement. And the authors express their gratitude to Prof. Taro Toyoda of Univ. of Electro-
Communications for the solar simulator and the specific surface area measurements and his helpful discussion.
[1] B. O'Regan and M. Grätzel, Nature 353, 737 (1991).

[2] Y. Chiba, A. Islam, Y. Watanabe, R. Komiya, N. Koide, and L. Han, Jpn. J. Appl. Phys. 45, L638 (2006).

[3] A. B. Kashyout, M. Soliman, M. El Gamal, and M. Fathy, Mat. Chem. Phys. 90, 230 (2005).

[4] N. Kopidakis, E. A. Schiff, N-G. Park, J. van de Lagemaat, and A. J. Frank, J. Phys. Chem. B 104, 3930 (2000).

[5] S. Nakade, S. Kambe, T. Kitamura, Y.wada, and S. Yanagida, J. Phys. Chem. B 105, 9150 (2001).

[6] M. Nada, T. Gonda, Q. Shen, H. Shimada, T. Toyoda, and N. Kobayashi, Jpn. J. Appl. Phys. 48, 025505 (2009).

[7] Y. B. Tang, Z. H. Chen, H. S. Song, C. S. Lee, H. T. Cong, H. M. Cheng, W. J. Zhang, I. Bello, and S. T. Lee, Nano Lett. 8, 4191 (2008).
[8] R. Morita, T. Narumi, and N. Kobayashi, Jpn. J. Appl. Phys. 45, 2525 (2006).

[9] M. S. Minski, M. White, and E. L. Hu, Appl. Phys. Lett. 68, 1531 (1996)

[10] C. Youtsey, L. T. Romano, and I. Adesida, Appl. Phys. Lett. 73, 797 (1998).

[11] M. K. Nazeeruddin, A. Kay, I. Rodicio, R. HumphryBaker, E. Muller, P. Liska, N. Vlachopoulos, and M. Grätzel, J. Am. Chem. Soc. 115, 6382 (1993).

[12] C.-Y. Chen, H.-C. Lu, C.-G. Wu, J.-G. Chen, and K.-C. Ho, Adv. Funct. Mater. 17, 29 (2007).

[13] K. S. Finnie, J. R. Bartlett, and J. L. Woolfrey, Langmuir 14, 2744 (1998). 